DOI: $10.14451 / 1.184 .26$

\title{
ФОРМИРОВАНИЕ АНТИКРИЗИСНОЙ МАРКЕТИНГОВОЙ СТРАТЕГИИ ОРГАНИЗАЦИИ В НЕФТЕГАЗОВОЙ ОТРАСЛИ
}

\author{
(c) 2020 Семенова Айталина Эдуардовна \\ магистрант кафедры «Менеджмент» \\ СВФУ им. М. К. Аммосова, Россия, Якутск \\ E-mail: SemenovaAita21@mail.ru \\ (c) 2020 Федорова Нюргуяна Аркадьевна \\ кандидат экономических наук, доцент кафедры «Менеджмент» \\ СВФУ им. М.К. Аммосова, Россия, Якутск \\ E-mail:nurguyana@mail.ru
}

В статье рассматриваются проблемы формирования антикризисной маркетинговой стратегии предприятия, разработаны мероприятия по стратегии развития предприятия, которые организация может использовать с целью занять наиболее выгодную позицию на рынке. Актуальность статьи связана с постановкой задачи выбора эффективной антикризисной маркетинговой стратегии предприятия нефтегазовой отрасли в современных нестабильных рыночных условиях экономики.

Ключевые слова: маркетинговая стратегия, стратегические цели, стратегия развития, комплекс маркетинговых средств, виды маркетинговых стратегий, нефтегазовый комплекс.

\section{Введение}

Антикризисная маркетинговая стратегия является эффективным и надежным инструментом развития компании. При разработке стратегии особое внимание уделяется оценке положения предприятия, его конкурентным позициям на рынке. Необходимо проведение анализа всех внешних и внутренних факторов.

Стратегия маркетинга - это составная часть всего стратегического управления предприятием, это план его деловой активности. Ее основная задача заключается в поддержании и развитии процесса производства, интеллектуального потенциала сотрудников фирмы, в повышении ассортимента и качества производимых товаров, в освоении новых рынков, увеличении сбыта и, в конечном счете, в повышении эффективности деятельности [3, с. 72].

В условиях антикризисного управления маркетинговые стратегии формируются набором маркетинговых инструментов, предопределяющих рыночную инфраструктуру. В общих чертах, комплекс маркетинговых средств представлен на рисунке 1.

Выделяют следующие виды маркетинговых стратегий в антикризисном управлении:

- стратегия возвращения компании в свою рыночную нишу;

- стратегия расширения рынка сбыта;

- стратегия развития товара или расширения ассортимента;

- стратегия диверсификации;

- стратегия ухода с рынка.

Также выделяют различные маркетинговые

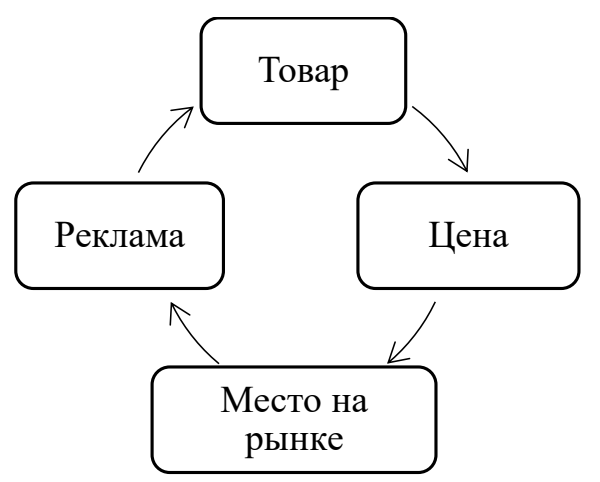

Puc. 1. Комплекс средств маркетинга в антикризисном управлении 
стратегии развития рынка сбыта продукции.

Стратегии сбытовой политики предприятия представлены на рисунке 2 и на матрице Ансоффа (рисунок 3).

Маркетинговые стратегии антикризисного управления проходят ряд последовательных этапов. Выделяют 4 основные стадии формирования маркетинговых стратегий (таблица 1).
Таким образом, антикризисная маркетинговая стратегия является основным направлением усилий организации по преодолению кризиса за счет маркетинговых возможностей.

Рассмотрим возможности применения вышеуказанного методического инструментария для предприятия нефтегазового сектора Республики Саха (Якутия).

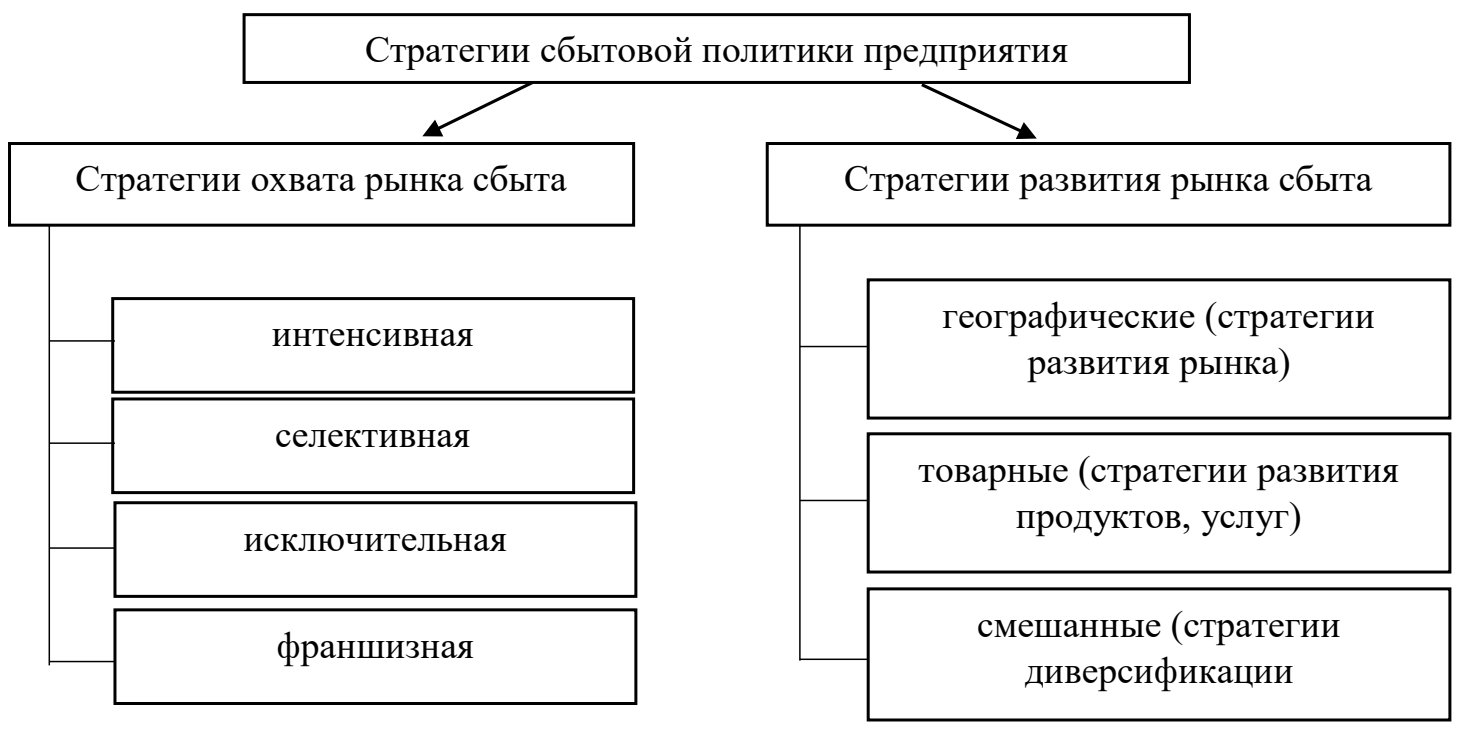

Puc. 2. Стратегии сбытовой политики предприятия

\begin{tabular}{|c|c|c|c|}
\hline & \multicolumn{2}{|c|}{ Рынки } \\
\hline & & Старый рынок & Новый рынок \\
\hline \multirow{2}{*}{ Товары } & $\begin{array}{l}\text { Старый } \\
\text { товар }\end{array}$ & $\begin{array}{c}\text { СТРАТЕГИЯ БОЛЕЕ ГЛУБОКОГО } \\
\text { ПРОНИКНОВЕНИЯ }\end{array}$ & СТРАТЕГИЯ РАЗВИТИЯ ГРАНИЦ РЫНКА \\
\hline & $\begin{array}{l}\text { Новый } \\
\text { товар }\end{array}$ & $\begin{array}{c}\text { СТРАТЕГИЯ РАЗВИТИЯ } \\
\text { НОМЕНКЛАТУРЫ }\end{array}$ & СТРАТЕГИЯ ДИВЕРСИФИКАЦИИ \\
\hline
\end{tabular}

Puc. 3. Матрица Ансоффа

Таблица 1.4 стадии формирования маркетинговых стратегий

\begin{tabular}{|l|l|}
\hline \multicolumn{1}{|c|}{ Стадии } & \multicolumn{1}{|c|}{ Характеристика } \\
\hline $\begin{array}{l}\text { 1. Анализ маркетинговых } \\
\text { возможностей организации }\end{array}$ & $\begin{array}{l}\text { Оценка сильных и слабых сторон организации, ее преимуществ от } \\
\text { функционирования на рассматриваемом рынке, возможные угрозы и } \\
\text { риски. }\end{array}$ \\
\hline 2. Отбор целевых рынков & $\begin{array}{l}\text { Рассматривает положительные и отрицательные стороны рынка, его } \\
\text { потребительский состав, потребность в продукции, на которые специа- } \\
\text { лизируется организация, и анализ спроса и предложения. }\end{array}$ \\
\hline $\begin{array}{l}\text { 3. Разработка основных положений } \\
\text { маркетинговой программы }\end{array}$ & $\begin{array}{l}\text { Формирование ценовой политики, методов вывода товара на рынок и } \\
\text { жей товаров, определение рекламной компании. }\end{array}$ \\
\hline $\begin{array}{l}\text { 4. Утверждение и реализация } \\
\text { маркетинговых программ }\end{array}$ & $\begin{array}{l}\text { Обоснование сформированных программ с точки зрения антикризис- } \\
\text { ного управления и общей стратегии организации. }\end{array}$ \\
\hline
\end{tabular}




\section{Основная часть}

Россия находится на восьмом месте по запасам нефти, и на третьем - по ее добыче. Но в нефтегазовом комплексе также существует ряд проблем, которые требуют своевременного решения:

- низкий уровень нефтепереработки;

- высокая себестоимость добычи сырья;

- плохая горно-геологическая, а также природно-климатическая разработка и разведка;

- поддержка стабильного налогового режима;

- отсутствие введения новейших и современных технологий;

- истощение уже имеющихся месторождений;

- незначительное количество инвестиций в нефтегазовый комплекс;

- отсутствие необходимых условий для гарантирования реализации крупных проектов;

- создание условий, которые бы могли гарантировать реализацию крупномасштабных инвестиционных проектов;

- внедрение современных и инновационных технологий;

- отсутствие специалистов в данной сфере с высоким уровнем квалификации.

Тем не менее Россия, безусловно, располагает всеми необходимыми возможностями для того, чтобы находится на высоте на мировом рынке энергоносителей. Но для этого в обязательном порядке необходимо развивать и внедрять технологии, формировать дополнительную инфраструктуру и проводить анализ всех экспортных направлений. Также государству необходимо предоставлять поддержку в виде различных преференций и налоговых льгот.

Основное влияние на формирование доходов нефтегазового сектора оказывают мировые цены на нефть и природный газ. В настоящее время ценообразование на нефть осуществляется в ходе биржевых торгов.

Для анализа динамики мировых цен нефти используется простое среднее спотцены основных маркерных сортов: Brent - Лондонской нефтяной бирже (IPE); WTI(West Texas Intermediate), торгуется на Нью-Йоркской товарной бирже (NYMEX) и Dubai - Сингапурской международной товарной бирже (SIMEX).

Ценообразование на российские сорта нефти устанавливается аналитически с привязкой (дисконтом) к нефти сорта Brent. Динамика средних цен нефти марки Brent в долларах США за баррель 2015-2019 гг. представлена на рисунке 4.

В январе 2020 г. мировые цены не нефть марки Brent снизились более чем на $15 \%$. Главной на рынке произошли из-за опасений нарушения баланса спроса и предложения международной новостью истекшего периода стала ситуация со вспышкой эпидемии коронавируса 2019-nCoV в Китае, где из-за распространения коронавируса ввели ограничения на движение транспорта и закрыли ряд промышленных предприятий.

Цена нефти Brent на 20 марта составляла на минимуме \$26,82 за баррель, показав падение на 57,7\% по сравнению с 2019 г. Стоимость нефти марки WTI опускалась до $\$ 22,41$ за баррель.

При текущих ценах на нефть эффективность сланцевых проектов будут снижаться и будут закрываться. Ряд компаний, связанных со сланцевой добычей, уже прекращает свою работу на сегодняшний день. Сегодняшняя ситуация на рынке приведет новой балансировке рынка.

Цены на нефть определяют стоимость нефтепродуктов - бензина, дизтоплива и пр.

Также причинами изменения стоимости нефтепродуктов, особенно для конечных пользователей, являются: сезонность, сокращение

\section{Цена, USD}

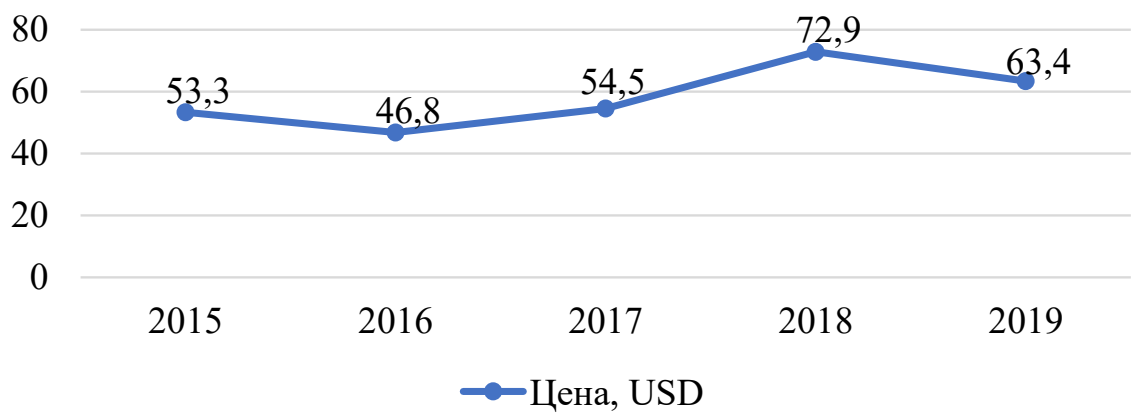

Puc. 4. Динамика средних цен на нефть марки Brent за 2015-2019 гг. 
продаж товара, купле-продажа или капитальный ремонт НПЗ, изменение активов ведущих производителей нефтепродуктов, природных факторов, внешнеэкономических факторов и других причин.

Стоимость на нефтепродукты в разных субъектах Российской Федерации значительно разняться. В таблице 2 представлены средние цены на АЗС на нефтепродукты в регионах России на 01.01.2020 г.

В качестве примера рассмотрим AO «Саханефтегазсбыт», который является основным участником рынка нефтепродуктов Республики Саха (Якутия), осуществляющий стабильный завоз горюче-смазочных материалов для нужд бюджетной сферы, населения и мелкооптовых потребителей региона.

АО «Саханефтегазсбыт» - вертикальноинтегрированная компания, которая придерживается концепции социально-этического маркетинга.
Основными видами деятельности Общества являются:

- оптово-розничная реализация нефтепродуктов;

- оказание услуг по приему, складским операциям и хранению нефтепродуктов.

Основные конкуренты АO «Саханефтегазсбыт» на рынке Республики Саха (Якутия):

- по реализации нефтепродуктов через сеть АЗС - ОАО НК «Туймаада-нефть», ООО НК «Сибойл», ОАО «ЯТЭК», ООО «Паритет»;

- по оптовой реализации нефтепродуктов ОАО «ЯТЭК», ОАО НК «Туймаада-нефть»;

- по оказанию приемо-складских услуг и хранению нефтепродуктов - ОАО НК «Тумааданефть».

Рассмотрим всех конкурентом и определим их доли в рынке (таблица 3).

Исходя из данной таблицы, мы видим, что большую долю рынка $(53,78 \%)$ занимает АО «Саханефтегазсбыт» он является лидером на

Таблица 2. Средние цены на АЗС на нефтепродукты в регионах России на 01.01.2020 г., руб./литр

\begin{tabular}{|c|c|c|c|c|}
\hline & АИ-92 & АИ-95 & ДТ (летнее) & ДТ (зимнее) \\
\hline \multicolumn{5}{|c|}{ Центральный федеральный округ } \\
\hline Москва & 42,87 & 47,07 & 45,64 & 47,49 \\
\hline \multicolumn{5}{|c|}{ Северо-Западный федеральный округ } \\
\hline Санкт-Петербург & 42,76 & 46,00 & 47,14 & 48,83 \\
\hline \multicolumn{5}{|c|}{ Южный федеральный округ } \\
\hline Республика Крым & 44,01 & 48,01 & 48,15 & 48,56 \\
\hline \multicolumn{5}{|c|}{ Северо-Кавказский федеральный округ } \\
\hline Ставропольский край & 44,77 & 47,93 & 44,94 & 47,52 \\
\hline \multicolumn{5}{|c|}{ Приволжский федеральный край } \\
\hline Пермский край & 43,16 & 46,01 & 46,60 & 48,87 \\
\hline \multicolumn{5}{|c|}{ Уральский федеральный округ } \\
\hline Ханты-Мантийский автономный округ & 43,82 & 46,12 & - & 52,21 \\
\hline \multicolumn{5}{|c|}{ Сибирский федеральный округ } \\
\hline Новосибирская область & 41,25 & 44,36 & 46,58 & 49,74 \\
\hline \multicolumn{5}{|c|}{ Дальневосточный федеральный округ } \\
\hline Республика Саха (Якутия) & 58,31 & 59,51 & 63,03 & 63,03 \\
\hline
\end{tabular}

Таблица 3. Конкуренты АO «Саханефтегазсбыт»

\begin{tabular}{|l|c|c|}
\hline \multicolumn{1}{|c|}{ Наименование } & Выручка, тыс. p. & Удельный вес \\
\hline ООО НК «Туймаада-нефть» & 4033266 & $16,86 \%$ \\
\hline ООО НК «Сибойл» & 1051000 & $4,39 \%$ \\
\hline ОАО «ЯТЭК» & 5869899 & $24,53 \%$ \\
\hline ООО «Паритет» & 104260 & $0,44 \%$ \\
\hline АО «Саханефтегазсбыт» & 12866927 & $53,78 \%$ \\
\hline ИТОГО & 23925352 & $100 \%$ \\
\hline
\end{tabular}


данном рынке. Т.к. является поставщиком Правительства Республики Саха (Якутия) по завозу, приему, отпуску и хранению светлых нефтепродуктов, а также нефтяного и котельного топлив для нужд жизнеобеспечения Республики Саха (Якутия), также имеет АЗС на территории Республики. ОАО «ЯТЭК» и ООО НК «Туймаада-нефть» имеют достаточно большую долю на рынке, $24,53 \%$ и $16,86 \%$ соответственно. Наименьшую долю имеют ООО НК «Сибойл» и ООО «Паритет», 4,39\% и $0,44 \%$ соответственно.

Далее составим конкурентную карту $\mathrm{AO}$ «Саханефтегазсбыт» (таблица 4).

Анализ показал, что АО «Саханефтегазсбыт» значительно превосходит ОАО «ЯТЭК», ООО НК «Туймаада-нефть», ООО «Сибойл» и ООО «Паритет» как по характеристикам услуг, так и по другим показателям. Основными конкурентами исследуемого предприятия в данной отрасли являются: ООО НК «Тумаада-нефть» и ОАО «ЯТЭК».

АО «Саханефтегазсбыт» лидер на данном рынке с неизменившейся позицией. Если Общество не будет изменять данную позицию, то его может обогнать ОАО «ЯТЭК» по следующим показателям:

- качество нефтепродуктов;

- имидж;

- высокая социальная обеспеченность кадрового состава.

АО «Саханефтегазсбыт» стремится сохранить лидерство, склонен продолжать наступле- ние и обострять борьбу с основными конкурентами. ОАО «ЯТЭК» имеет сильную конкурентную позицию, имеет шансы занять место лидера. ООО НК «Туймаада-нефть» и ООО «Сибойл» будут вести активные оборонительные действия, в зависимости от ситуации даже переходить в атакующие действия. ООО «Паритет» старается защитить свою долю и сегмент. Далее определим сильные и слабые стороны АО «Саханефтегазсбыт» с возможностями и угрозами рынка, применив матрицу SWOT (таблица 5).

В таблице показаны сильные и слабые стороны АO «Саханефтегазсбыт», а также возможные угрозы и возможности предприятия. Можно сделать вывод о том, что одной из наиболее сильных сторон данного предприятия является лидерство по объемам добычи нефти в Республике, что, безусловно, даёт преимущество перед конкурентами.

Основные пути совершенствования маркетинговой деятельности предприятия можно разделить на стратегические и тактические. Стратегические представляют собой изменение подхода управления, а тактические - перераспределение функций и модифицирование структуры отдела маркетинга (таблица 6).

Только при минимальных затратах и максимальной отдаче может быть достигнута максимальная эффективность маркетинговой деятельности. Важно сравнить затраты с ожидаемыми результатами.

Таблица 4. Конкурентная карта АО «Саханефтегазсбыт»

\begin{tabular}{|c|c|c|c|c|}
\hline \multirow{2}{*}{$\begin{array}{c}\text { Изменение доли } \\
\text { предприятия на рынке }\end{array}$} & \multicolumn{4}{|c|}{ Виды конкурентов (по доле рынка) } \\
\hline & Лидеры рынка & $\begin{array}{c}\text { Сильные } \\
\text { конкуренты }\end{array}$ & $\begin{array}{c}\text { Слабые } \\
\text { конкуренты }\end{array}$ & Аутсайдеры \\
\hline $\begin{array}{l}\text { Предприятие с быстро улуч- } \\
\text { шающейся конкурентной } \\
\text { позицией }\end{array}$ & & & $\begin{array}{c}\text { ооо НК } \\
\text { «Туймаада-нефть» }\end{array}$ & \\
\hline $\begin{array}{l}\text { Предприятие с улучшающей- } \\
\text { ся конкурентной позицией }\end{array}$ & & ОАО «ЯТЭК & ООО «Сибойл» & \\
\hline $\begin{array}{l}\text { Предприятие с неизменив- } \\
\text { щейся позицией }\end{array}$ & $\begin{array}{c}\text { АО «Саханефте- } \\
\text { газсбыт» } \\
\vdots\end{array}$ & & $\downarrow$ & ООО «Паритет» \\
\hline $\begin{array}{l}\text { Предприятие с ухудшающей- } \\
\text { ся конкурентной позицией }\end{array}$ & $\downarrow$ & & & $\downarrow$ \\
\hline $\begin{array}{l}\text { Предприятие с быстро ухуд- } \\
\text { шающейся конкурентной } \\
\text { позицией }\end{array}$ & & & & \\
\hline
\end{tabular}


Таблица 5. SWOT-анализ АO «Саханефтегазсбыт»

\begin{tabular}{|c|c|}
\hline Сильные стороны & Слабые стороны \\
\hline $\begin{array}{l}\text { 1. поставщик Правительства РС (Я) по завозу, при- } \\
\text { ему, отпуску и хранению светлых нефтепродуктов, } \\
\text { а также нефтяного и котельного топлив для нужд } \\
\text { жизнеобеспечения РС (Я); } \\
\text { 2. введение зонирования цен нефтепродуктов на } \\
\text { территории реализации РС (Я); } \\
\text { 3. наличие нефтесклада в п. Нижний-Бестях, доступ- } \\
\text { ность к железнодорожным перевозкам; } \\
\text { 4. наличие крупного емкостного парка по хранению } \\
\text { нефтепродуктов; } \\
\text { 5. высокая социальная обеспеченность кадрового } \\
\text { состава Общества. }\end{array}$ & $\begin{array}{l}\text { 1. государственное регулирование цен на нефтепро- } \\
\text { дукты; } \\
\text { 2. недостаточный объем собственных оборотных } \\
\text { средств предприятия; } \\
\text { 3. высокий уровень сезонности потребления нефте- } \\
\text { продуктов; } \\
\text { 4. неразвитая система взаимоотношений с потенци- } \\
\text { альными инвесторами. }\end{array}$ \\
\hline Возможности & Угрозы \\
\hline $\begin{array}{l}\text { 1. строительство нефтесклада в п. Нижний Бестях } \\
\text { позволит вывести из оборота и снизить затраты на } \\
\text { содержание аварийного емкостного парка на Якут- } \\
\text { ской нефтебазе и нефтебазах центральной группы } \\
\text { улусов РС (Я); } \\
\text { 2. строительство КАЗС в населенных пунктах, объе- } \\
\text { мы реализации нефтепродуктов, в которых позволят } \\
\text { обеспечить рентабельную работу КАЗС; } \\
\text { 3. изменение конфигурации транспортной сети, } \\
\text { обеспечивающих видов транспорта и схем завоза } \\
\text { нефтепродуктов на территории РС (Я); } \\
\text { 4. изменения территориальной и отраслевой органи- } \\
\text { зации региональной экономики и общества, обу- } \\
\text { славливающие изменения в структуре потребления } \\
\text { нефтепродуктов и изменения географии размещения } \\
\text { центров их потребления. }\end{array}$ & $\begin{array}{l}\text { 1. снижение мировых цен на нефтепродукты; } \\
\text { 2. слабая развитая структура транспортировки не- } \\
\text { фтепродуктов (короткий период навигации, сезон- } \\
\text { ность перевозок); } \\
\text { 3. увеличение доли рынка ОАО НК «Туймаада- } \\
\text { нефть», ООО «Сибойл», ОАО «ЯТЭК», ООО «Паритет»; } \\
\text { 4. нестабильность мирового рынка нефтепродуктов } \\
\text { и ее отражение на внутреннем рынке РФ, что стиму- } \\
\text { лирует экономику к использованию альтернативных } \\
\text { источников энергии; } \\
\text { 5. увеличение объемов производства и потребления } \\
\text { альтернативных видов моторного топлива. }\end{array}$ \\
\hline
\end{tabular}

Таблица 6. Стратегия развития $\mathrm{AO}$ «Саханефтегазсбыт»

\begin{tabular}{|c|c|}
\hline Цели & Направления \\
\hline Глобальные (миссия) & $\begin{array}{l}\text { Удовлетворять потребности потребителей нефтепродуктов и быть гарантом нефте- } \\
\text { продуктообеспечения производительных сил на территории Арктики, обеспечивая } \\
\text { сбалансированный прогресс Общества, повысить качество жизни народов Севера. }\end{array}$ \\
\hline Стратегические & $\begin{array}{l}\text { - Завоевать лидирующее положение на данном сегменте; } \\
\text { - Увеличить объем продаж за счет качества производимой продукции и скидок, и } \\
\text { привлечь новых потребителей; } \\
\text { - Закупить автотранспорт; } \\
\text { - Провести эффективные маркетинговые мероприятия. }\end{array}$ \\
\hline Тактические & $\begin{array}{l}\text { - Привлечь новых потребителей; } \\
\text { - Изменить и расширить ассортимент продукции; } \\
\text { - Направить рекламу на индивидуального потребителя для решения следующих } \\
\text { задач: борьба с конкурентами; привлечение новых потребителей; } \\
\text { - Провести усиленный прием на работу требуемых рабочих и специалистов. }\end{array}$ \\
\hline
\end{tabular}

Исходя из миссии организации АО «Саханефтегазсбыт», стратегические цели были поставлены следующим образом:

- повышение рентабельности до 25\%;

- увеличение доли рынка до 15\%;

- вытеснение основных конкурентов за счет качественных поставок материалов и сырья в более короткие сроки;

- улучшение имиджа компании;

- улучшение социальных условий для пер- сонала предприятия, в том числе улучшение мотивации сотрудников;

- увеличение собственного автотранспортного парка для перевозки нефтепродуктов;

- финансовая стабильность.

Далее была определена стратегическая цель маркетинга $\mathrm{AO}$ «Саханефтегазсбыт».

Общей стратегической целью маркетинга АО «Саханефтегазсбыт» является сохранение и оптимизация централизованного управления 
нефтебазами и АЗС в целях обеспечения потребителей нефтепродуктами и услугами, связанными с нефтепродуктообеспечением, а также получение прибыли.

SWOT-анализ AO «Саханефтегазсбыт» показал, что существует множество проблем, решить которые можно путем развития и продвижения бренда. Они позволят раскрыть существующий потенциал бренда, что в последующем позволит реализовать множество возможностей внешней среды, усилить сильные стороны, уменьшить количество слабых сторон и минимизировать внешние угрозы.

АО «Саханефтегазсбыт» следует пересмотреть политику продвижения товара, т.к. она незаметна. Например, можно рекламировать услуги, предоставляемые компанией среди населения при помощи средств массовой информации. Необходимо совершенствование рекламной деятельности, направленное на увеличение объемов сбыта.

Также рекомендуется формирование фонда собственных оборотных средств. Отсутствие фонда собственных оборотных средств $\mathrm{AO}$ «Саханефтегазсбыт» не позволяет финансово обеспечивать годовой завоз нефтепродуктов в навигационный период, а также отражается на конкурентоспособности предприятия.

По состоянию на 2018 год Общество имеет отрицательную величину собственных оборотных средств в размере 1051772 тыс. $р$.

Возможно внедрение маркетинговых инноваций (акции, льготное обслуживание, системы скидок и др.)

Используем матрицу Ансоффа для рекомендации выбора наиболее подходящей стратегии для АО «Саханефтегазсбыт» и представим в таблице 7.
Исходя из таблицы 7 рассмотрим рекомендации по выбору стратегии по матрице Ансоффа:

1) Стратегия проникновения на рынок, т.е. совершенствование деятельности предприятия. Предприятию рекомендуется обратить внимание на маркетинговые мероприятия для существующих товаров на данном рынке, необходимо исследовать целевой рынок предприятия и разработать мероприятия по продвижению продукции, которые увеличат эффективность деятельности предприятия на данном рынке. Например, можно внедрить ценовые акции, и постепенно повышать цены рамках ценовой эластичности. При данной стратегии предприятие укрепит свое положение на рынке за счет полного охвата рынка. Стратегия проникновения на рынок является стратегией концентрированного роста.

2) Стратегия развития продукта, подразумевает разработку новых товаров, услуг или совершенствование существующих товаров, услуг целью которого является увеличение продаж. Данная стратегия наиболее предпочтительна с точки зрения минимизации риска, т.к. предприятие будет осуществлять стратегию на уже знакомом рынке и потребители уже знакомы с брендом и у предприятия уже есть сформированный имидж. За счет сохранения доли на рынке, предприятие может увеличить свой доход и прибыль. Данная стратегия является стратегией интенсивного роста.

3) Стратегия развития рынка, предлагает осваивать новые рынки или новые сегменты рынка для существующих товаров, услуг. При данной стратегии можно расширить свой рынок, например открыть АЗС в улусах и районах Якутии. Данная стратегия более затратна и рискованна, чем предыдущие. Выйти на новые ге-

Таблица 7. Матрица Ансоффа.

\begin{tabular}{|c|c|c|c|}
\hline & \multicolumn{2}{|c|}{ Рынки } \\
\hline & & $\begin{array}{l}\text { Старый рынок (рынок бензина, маз- } \\
\text { ута, автомобильных масел) }\end{array}$ & $\begin{array}{l}\text { Новый рынок (рынок бункерного } \\
\text { топлива, рынок авиатоплива) }\end{array}$ \\
\hline \multirow[t]{2}{*}{ Товары } & $\begin{array}{l}\text { Старый товар (мас- } \\
\text { ла, бензин, мазут, } \\
\text { дизельное топливо) }\end{array}$ & $\begin{array}{l}\text { Модернизация и повышение эф- } \\
\text { фективности Общества, расширение } \\
\text { фасовочных линий (для масел), реа- } \\
\text { лизация программы расширения и } \\
\text { модернизации терминалов, развитие } \\
\text { розничной сети АЗС за пределами } \\
\text { города Якутска. }\end{array}$ & $\begin{array}{l}\text { Географическое расширение рынка, } \\
\text { увеличение предложения выпускае- } \\
\text { мой продукции на новых рынках. }\end{array}$ \\
\hline & $\begin{array}{l}\text { Новый товар } \\
\text { (бункерное топли- } \\
\text { во, авиатопливо, } \\
\text { топливо) }\end{array}$ & $\begin{array}{l}\text { Совершенствование товара с целью } \\
\text { увеличения продаж, улучшение экс- } \\
\text { плуатационных свойств топлива. }\end{array}$ & $\begin{array}{l}\text { Расширение ассортимента, укре- } \\
\text { пление позиций на новых рынках, } \\
\text { увеличение объемов реализации. }\end{array}$ \\
\hline
\end{tabular}


ографические рынки будет трудно, т.к. они заняты конкурентами. Стратегия развития рынка является стратегией экстенсивного роста.

4) Стратегия диверсификации, предполагает разработку новых товаров для новых рынков. Данная стратегия наиболее рискованна и дорогостоящая, однако обеспечит прибыль, стабильность и устойчивость предприятия в будущем. Предприятие должна инвестировать и выделять дополнительные ресурсы для развития нового бизнеса.

\section{Заключение}

Изучив внешние и внутренние среды АО «Саханефтегазсбыт» можно сделать вывод, что существует множество проблем, решить которые можно путем развития и продвижения бренда. Они позволят раскрыть существующий потенциал бренда, что в последующем позволит реализовать множество возможностей внешней среды, усилить сильные стороны, уменьшить количество слабых сторон и минимизировать внешние угрозы.

\section{Библиографический список}

1. Зуб, А.Т. Антикризисное управление организацией: Учебное пособие / А.Т. Зуб, Е.М. Панина.- М.: Форум, 2018.- $239 \mathrm{c}$.

2. Ивасенко, А.Г. Антикризисное управление: Учебное пособие / А.Г. Ивасенко, Я.И. Никонова, М.В. Каркавин.- М.: КноРус, 2018. - 208 с

3. Маркетинг. / Под ред. проф. Э.А. Уткина - М.: Ассоциация авторов и издателей «Тандем». Издательство ЭКМОС, 1998. - 320 с.

4. Орехов В.И., Балдин К.В. Антикризисное управление: М.: Инфра-Иженерия, 2015.- 496 с.

5. Россия в цифрах. 2019: Крат. стат. сб. / Федеральная служба государственной статистики (Росстат). М., 2019. Сайт: https://www.gks.ru/free_doc/doc_2019/rusfig/rus19.pdf

6. Сайт АО «Саханефтегазсбыт» [Электронный ресурс] - http://www.sngs.ykt.ru/ 